\title{
REESCRIBIENDO EL VACÍO: COLONIALISMO Y FEMINISMO FRENTE A LA CONQUISTA DE LA TIERRA VIRGEN. EL CASO DE JOSEPH CONRAD Y CLAIRE LEJEUNE ${ }^{1}$
}

\author{
Almudena María Gómez Seoane y Cecilia Fernández Santomé. \\ Universidad de Santiago de Compostela \\ almudenagomez@hotmail.com cfsantome@hotmail.es
}

\begin{abstract}
Resumen: Este artículo gira en torno al tratamiento de dos procesos singulares de configuración identitaria, encarnados por la autora belga Claire Lejeune y el personaje de ficción Marlow (Heart of Darkness, de Joseph Conrad). La ansiedad ante la falta de referentes, la necesidad de forjarse un perfil público que legitime el discurso personal y las estrategias concebidas hermanan a ambos. Violentado o moldeado por la fuerza fálica o poética, el terreno yermo del continente inexplorado y de la hoja del cuaderno se ofrecen - respectivamente- al agente colonial y a la filósofa feminista. Creación ex nihilo aplicada a literatura y colonización.

Palabras clave: Creatividad, blanco, colonizar, ansiedad, identidad.

Title in English: Rewriting the emptiness: colonialism and feminism on the conquest of the blank space. The case of Joseph Conrad and Claire Lejeune

Abstract: This article aims to reflect the treatment of identity process in both the Belgian writer Claire Lejeune and the fictional character of Marlow (in Joseph Conrad's Heart of Darkness). They share the anxiety of the lack of references, as well as the neccesity of being made a public profile which supports their personal speech. Molded by the poetical or phallical strength, the blank page and the unexplored continent seduce both the feminist philosopher and the colonial agent. Ex nihil creation applied to literature and colonization.

Keywords: Creativity, blank, colonize, anxiety, identity.
\end{abstract}

"In principio creavit Deus caelum et terram. Terra autem. Eraí inanis et vacua, et tenebrae super faciem abyssi, et spiritus Dei ferebatur super aquas".

(Génesis, 1, 1-2)

Desde la noche de los tiempos, el ser humano se ha visto confrontado al vacío, al espacio yermo y al caos, sometido a la desazón provocada por lo inaprensible e incontrolable. Progresivamente, y lejos de abandonarse a la fuerza centrífuga de lo desconocido, se ha

Date of reception: 3 June 2011

Date of acceptance: 31 July 2011

Odisea, $n^{\circ} 12$, ISSN 1578-3820, 2011, 307-318 
abastecido de diversas armas -más o menos poderosas- a través de las cuales aprehender dichas realidades. Dioses, leyendas, relatos míticos o fábulas no son más que vestigios de esos amuletos protectores, de esos círculos de seguridad de los que se rodearon nuestros ancestros (y de los que seguimos echando mano con mayor o menor frecuencia), sirviéndoles para enfrentarse y hacer suyo un mundo lleno de enigmas y dudas, de preguntas y respuestas esquivas. Dominando la oscuridad por procuración, a través de la mediación divina o fantástica, la posibilidad de dar sentido a lo que de él carece contribuyó a aumentar progresivamente el índice de control sobre uno mismo y sobre la realidad -tangible o intangible-.

Sin embargo, el desplazamiento del centro de gravedad moral de la entidad suprema a la persona invirtió el rol legitimador de la primera, transfiriéndoselo al hombre y a la mujer (en tanto que delegados del Creador, productos perfectos y acabados de la inspiración divina). El Humanismo occidental, la confianza antropocentrista, derivaron en numerosas tentativas de sistematización no mítica de todo aquello asociado a la nada, a lo ininteligible o al desorden existencial. Las expediciones financiadas a partir del siglo XV por las principales coronas europeas, en la búsqueda de nuevas tierras, de nuevos retos a los que enfrentarse o de nuevas realidades que asimilar son un buen ejemplo de dicha voluntad naciente.

Pero no sólo se trataba de hacer suya la nada física, sino también la nada intelectual. Y la profusión de teorías metafísicas sobre la condición humana y sus entresijos, sobre el ser y su esencia se sucedieron durante siglos. Progresivamente, el espacio en blanco, el vacío, dejó de ser una abstracción aterradora que evitar a toda costa con la ayuda de las más diversas teorías. Poco a poco, lo aparentemente yermo comenzó a ser contemplado como algo positivo, un inmenso terreno por explorar y que ofrecía grandes posibilidades interpretativas y de acción.

El caos representado por esa nada física o metafísica, la inestabilidad de la posición humana frente a ese poderoso agujero negro de lo desconocido, derivó entonces en una conceptualización de una nada creadora. Como si del más puro nihilismo positivado se tratase, la tábula rasa representada por ese abismo de lo no conocido que se abre a cada paso ante el ser humano se convirtió en productora de significado.

Erigiéndose en el dios de su propio destino (tomemos como ejemplo la creación del superhombre nietzscheano), destruyendo simbólicamente esa serie de figuras normalizadoras de su existencia a lo largo de los siglos, el ser humano se aplicó en la creación ex-nihilo.

[...] Le nihil nous entraine dans la maitrise de la vie. II brille dans le noir et nous dit: soit paisible, car il faut conjuguer l'angoisse et la raison, 1 'inanité et la forcé rationnelle. (Russ: 1998, 16)

Producir tomando la nada como base, aventurarse en el terreno fangoso de la ausencia de referencias, de la absoluta 'obligación' de innovar para seguir avanzando de forma titubeante entre las sombras implicaba un grado extra de esfuerzo y de originalidad. Una originalidad que no es sino -en mayor o menor medida- la base del principal motor de la acción humana: el deseo de obtener el reconocimiento de sus iguales.

La aptitud para innovar, para generar nuevas realidades fundamenta la capacidad de distinción de cada individuo. Y es que, tal y como el sociólogo francés Pierre Bourdieu ha 
ampliamente defendido (Le champ littéraire, Choses dites), la diferenciación es la condición necesaria para existir dentro de un determinado campo (ya sea en el plano social, cultural o económico). Procurarse una serie de rasgos característicos no es más que sentar las bases de una identidad propia.

Pero no sólo el individuo ha debido -y debe- luchar en pos de la distinción.

Las colectividades humanas se ven sometidas a este mismo principio de creación identitaria. En tanto que suma de particularidades individuales más o menos comunes, la nación, el país, la región o cualquier otro tipo de comunidad representa un marco global, una macroestructura dotada de personalidad propia frente a sus circundantes.

[...] A social movement is the process of the social construction of reality because, in the course of the repeated activation of relationships that link SMOs, a collective identity is formed and reinforced [...] (Phillips, 1991: 756)

La reafirmación del individuo sienta las bases de la consolidación de su grupo social y viceversa, debiendo ambos dotarse de caracteres que los identifiquen en este proceso retroalimentario. Si el ser humano echa mano para ello de una serie de atributos propios, de un cierto espacio físico- intelectual en el que se desarrolla y que le otorgan una cierta preeminencia sobre sus iguales, la nación (entendida de un modo próximo al sentido romántico del concepto) construye su esquema distintivo en tomo a un espacio físico definido en base a sus fronteras, a un himno, a una bandera y a una cultura ${ }^{2}$.

Del mismo modo que el individuo se ve impulsado a una constante renovación, actualizando y reforzando sus tomas de posición simbólicas, los pueblos han desarrollado a lo largo de los siglos estrategias de legitimación y defensa de su entramado identitario. Una de las más manidas ha sido -y es- el uso de la fuerza armada. Blandiendo los principios de patria, gloria y libertad, cientos y cientos de ejércitos se abandonan a la batalla. Y así, el hombre, héroe entregado a la causa, se convierte en el principal subsidiario de la reivindicación nacional. El refuerzo de las posturas que conlleva la victoria reafirma también la del artífice de la misma: el soldado. La guerra es, pues, el terreno en el que se dirime el peso específico de las potencias enfrentadas, saciando en buena medida la sed de reconocimiento del hombre que en ella participa. Configurando una enorme cadena de transmisión, la gloria, la celebridad y el éxito contribuyen a consolidar identidades (ya sean colectivas o individuales). Sin embargo, este esquema parece únicamente aplicable al varón. La mujer, constreñida en el espacio privado, ha visto mermada su capacidad de invención y reinvención, obligada a sutilizar sus ansias de representatividad y reconocimiento. El mito del hombre guerrero eclipsa al de la mujer en el hogar. "Underlying this myth is the belief that men are naturally fierce and warlike, while women, as mothers, have an affinity for peace" (Higonnet \& alii, 1987: 1).

La aventura colonizadora de las principales metrópolis occidentales - precedida por los viajes de exploración llevados a cabo ya en la Edad Modema- responde en esencia al

Sobre la configuración de la identidad nacional, véase el artículo de TORRES FEIJÓ, Elias L. «Contributos sobre o objecto de estudo e metodología sistémica. Sistemas literarios e literaturas nacionais» en ABUÍN GONZÁLEZ, Anxo y Anxo TARRÍO VARELA (ed.). Bases metodolóxicas para imha historia comparada das literaturas na Península Ibérica. Santiago de Compostela: USC, 2004.

Odisea, ${ }^{\circ} 12$, ISSN 1578-3820, 2011, 307-318 
patrón anterior. Intereses comerciales, científicos o religiosos se escondieron bajo el amplio paraguas legitimador de la pugna por una plaza de mérito en el plano europeo. Las fricciones continentales, el ansia de notabilidad de los distintos gobiernos fueron trasladados allén de sus fronteras. Demostraciones de fuerza (como el choque de intereses vivido en la batalla de Sedán) y potencial atestiguaron de la urgencia por consolidar de cara al exterior el concepto abstracto que cada una de las naciones se había foijado de sí misma.

La expansión colonial a la que dio el pistoletazo de salida la Conferencia de Viena (1885) no fue sino el fruto de la necesidad de escribir una nueva página de oro en la historia de cada uno de los países en liza. ¿Y qué mejor que hacerlo sobre el lienzo en blanco que ofrecía el continente africano? La pluma europea buscaba rellenar ese espacio inhóspito que para el hombre europeo representaba Africa, una tierra virgen y ajena a los fundamentos de la cultura metropolitana que "clamaba" por ser fertilizada. Esas tierras lejanas ofrecían a cada nación la posibilidad de aplicarse en el dominio del vacío abierto ante sí, demostrando su capacidad para hacer frente a la nada preexistente, explicándola, amansándola y haciéndola suya. Creación ex-nihilo de una nueva Europa transmediterránea y de un nuevo orden sociopolítico. La página en blanco simbolizada por el espacio a conquistar habló por primera vez a las metrópolis y lo hizo para farfullar su entrega a manos de las fuerzas coloniales.

De modo muy similar, la mujer occidental ha aprendido a manejar el silencio y la palabra en su favor. Obligada a expresarse durante siglos a través de discursos mediados por el hombre, con una voz extraña a la propia que bloqueaba sistemáticamente toda reivindicación identitaria, la víctima alienada ha desarrollado nuevos cauces de expresión. La progresión de una conciencia femenina o feminista ha facilitado el acceso de la mujer a los medios, a la notoriedad pública. Haciéndose escuchar para subvertir lo periférico de su situación, blandiendo la oscuridad de su posición dentro de la rueda de la Historia como un valor y no como un estigma, transformando la aridez del terreno social en un estímulo para levantar un nuevo orden.

Si bien el hombre colonizador occidental puede concebirse como una especie de guerrillero/ autor que trabaja sobre el frente de batalla/ hoja en blanco, la mujer se constituye de forma metafórica en la propia tela virgen, un agujero negro carente de una historia propia que lo legitime frente a su entorno (pero que, al mismo tiempo, desprende energía y presenta una incesante actividad interna). Ambos se mueven con cautela entre el silencio y la palabra. Y es que, en un cierto sentido, colonizador y feminista pretenden hacer del silencio palabra. En el caso del primero, una palabra -la del colonizado, la de la propia África- semejante a la suya propia. Una voz mimética, casi un eco lejano. Sometida durante siglos a una dinámica amo- esclavo muy similar, la mujer anhela algo diametralmente opuesto: hacer oír su propio discurso. Una aspiración formulada irónicamente por la crítica masculina siguiendo fórmulas tales como las siguientes, que avivaron el debate del sufragismo europeo:

«La femme ne veut plus obéir ? c'est done qu'elle veut commander. La femme prétend étre libre ? c'est done Phomme qui sera esclave [...]» Tel est leur raisonnement. (Laguerre, 1905: 4)

Dicha ansiedad femenina es mucho más evidente, si cabe, en el caso de las escritoras contemporáneas, enfrentadas a la tarea de ganarse un hueco en un canon constrictivo 
liderado por agentes masculinos. Sin referencias, sin una 'madre' cultural que las guíe, las autoras occidentales de nuestros días se han visto confrontadas a la orfandad del blanco existencial.

Curiosamente, si bien colonizador y mujer de letras se han enfrentado a un espacio igualmente desolador, son muchos los ejemplos de escritoras que han jugado a autoinfligirse el 'castigo' del silencio primigenio con un valor catalizador y subversivo. El explorador, imponiendo por su parte el silencio a los indígenas, echaba mano del mismo para garantizar el éxito de su empresa. La ausencia de expresión, metáfora de la página por escribir, se convierte en ambos casos en un instrumento al servicio de dos particulares combates identitarios.

Extrapolando la aventura colonizadora al ámbito de la literatura, no podemos olvidar algunas de las obras maestras de la literatura inglesa que reflejan la esencia del imperialismo. Así, E. M. Forster, Rudyard Kipling o el propio Joseph Conrad (con Heart of Darkness, en el que se basa este estudio) son fieles depositarios de dicha ideología. A través de una serie de personajes (¿alter ego de los autores?), retratan los entresijos del paso del hombre blanco por las colonias africanas o asiáticas. Todos ellos testimonios Acciónales de gran impacto que sitúan al lector frente a una especie de ensayo sobre la condición humana. Sobre una condición, la del hombre, que -al igual que la de la mujer- ofrece a menudo un terreno abonado a la reflexión. Claire Lejeune (1926-2008), una de las más notables escritoras contemporáneas de la Bélgica francófona (Age poétique, áge poliíique, Le livre de la san/r, Le livre de la mere, etc.), presenta una escritura basada en este mismo principio de introspección. Una literatura sobre la condición de la mujer y de la escritora, identidades que se solapan y se fusionan en su propia naturaleza.

Tomando como referencia uno de los textos más célebres de esta escritora (Le livre de la soeur, 1993) y el relato enmarcado de Marlow en Heart of Darkness (1902), desgranaré dos procesos paralelos de creación de un 'yo' propio. Y es que, aunque el uno no sea más que un personaje de ficción y Claire Lejeune, una autora de carne y hueso (lo que los sitúa en dos niveles diegéticos asimétricos), sus respectivos discursos en primera persona constituyen textos paralelos de auto-legitimación, de auto- explicación y de auto- reivindicación.

Este artículo está inspirado, pues, en uno de los principios esenciales de la Teoría de la Literatura y de la Literatura Comparada en tanto que disciplinas de estudio: la transversalidad en la perspectiva adoptada. De hecho, su ambición va más allá de la búsqueda anecdótica de conexiones entre diversos soportes de expresión cultural, trascendiendo a menudo las fronteras que determinan la autonomía relativa de los distintos campos culturales mediante la exploración de sus contactos y trasvases estético-temáticos. Partiendo de esta premisa, tienen mucho que ver con el análisis del desarrollo de las dinámicas de innovación y renovación que Pierre Bourdieu ha asociado con los elementos emergentes dentro un sistema dado. La 'urgencia distintiva' motiva en algunos casos la 'exotización* del discurso mediante la importación de recursos expresivos exógenos.

Sin embargo, la connivencia temático-simbólica entre la escritura de Lejeune y el relato de Marlow no sólo es el fruto de la puesta en práctica de una estrategia de préstamo intertextual articulada por la autora belga en aras de aumentar su capital simbólico mediante la referencia a un producto cultural ya legitimado. Es el testimonio de que el hecho literario, la obra, en su naturaleza de producto cultural es el resultado de la intersección de factores 
estructurales y superestructurales que contribuyen a consolidar a su responsable en una posición meritoria en el espacio o sistema en el que éste se desenvuelve. Y el trasvase o el préstamo entre diferentes tradiciones literarias es uno de sus más notables activos. Los ecos psicoanalíticos que podemos encontrar en ambas obras constituyen un punto de fuga que permite conectar dos etapas literarias, dos idiosincrasias, dos concepciones artísticas divergentes; y vincularlas de modo tangencial. A través de una aproximación inmanentista a los textos de referencia seleccionados, elaboraremos un estudio metodológicamente inspirado en la combinación de la teoría feminista y los conceptos del neomarxismo de Bourdieu (una alianza compleja, pero de gran productividad) que permita poner de manifiesto las dimensiones del subtexto común.

Así pues, la distancia -temporal e ideológica- aparente que separa las realidades de ambos textos no es óbice para encontrar un cierto nexo de unión en sus respectivos procesos de formación identitaria. El ensayo poético de Lejeune, planteado como una especie de retrato lírico- filosófico, presenta en sus primeros compases a una autora titubeante. De modo semejante, la trayectoria vital de Marlow parece un tanto errática a tenor de la presentación que de él nos ofrece Conrad. El inicio de sus respectivos discursos aparece cargado de un cierto desasosiego. Después de múltiples aventuras personales y profesionales, Marlow se halla ante una encrucijada: cumplir su sueño y labrarse un porvenir glorioso o abandonarse a la monotonía de su gris existencia. Le livre de la sceur presenta a una autora que busca, en primera persona, dar un nuevo giro de tuerca a un largo proceso de reflexión y conocimiento personal a través de la escritura.

El personaje de Marlow y Claire Lejeune comparten la ansiedad experimentada ante el espacio en blanco. Ante sus ojos se abre una puerta a una nueva etapa existencial y profesional, un abismo que promete desestabilizar un equilibrio previo más o menos logrado. Africa y el folio representan respectivamente un terreno que agrede con su desolación a la lógica de quienes a ellos se aproximan. Deseosos de conocer, de dotar de sentido, de buscar una nueva significación en lo desconocido, se sientan ante dos mapas (el físico y el textual) blandiendo sus mejores armas defensivas. Y es que, en efecto,

Marlow's attempts to impose some order and meaning on his Congo experience echoes the European project of civilizing the dark places of the earth and can be seen as a form of linguistic colonialism. (Panagopoulos, 1998: 84)

Si lo que escapa a nuestro control nos aproxima a la muerte y al caos, debemos desarrollar formas alternativas con las que neutralizarlo. El criterio de Héléne Cixous bien podría aplicarse a los dos casos que reclaman mi atención al sentenciar: "Écrire: pour ne pas laisser la place au mort, pour faire reculer 1'oubli, pour ne jamais se laisser surprendre par 1'ablme" (Cixous, 1977: 11).

Frente al pánico que suscita dicho abismo, sólo caben dos respuestas: la aceptación sumisa del mismo o el combate contra él. Llenándolo de contenido, haciendo de lo negro blanco y de lo blanco un arco iris de colores. Unidos por una misma voluntad creadora (ya sea a través del arte o de la organización política) que reactive su ritmo vital, el Marlow 'conradiano' y Claire Lejeune materializan dicha pulsión siguiendo caminos un tanto divergentes. 
Marlow se vale de su calidad de "hijo de la Gran Bretaña", miembro de la sociedad metropolitana y ostentador de un falo simbólico- real que lo imbuye de un cierto poder para dibujar una trayectoria vital ascendente en la búsqueda de la gloria social. Claire Lejeune, desprovista del aura otorgada por la posición fálica, debe procurarse nuevos medios que compensen dicha ausencia. Es por ello por lo que recurre al instrumento- falo por excelencia: la pluma del escritor (Gilbert y Gubar - 1984: 3- se preguntan "is a pen a metaphorical penis?"). Un elemento simbólico que le sirve para convertirse -en un gesto próximo al travestismo- en un explorador de la literatura al más puro estilo de Marlow. La gran diferencia estriba en que la mascarada utilizada por la escritora constituye el salvoconducto indispensable que la habilita al uso social de la palabra y, por la misma, a la acción directa. La manipulación del atributo por excelencia del escritor occidental -la pluma- camufla a Claire Lejeune bajo el manto de éste. Beneficiándose de una histórica posición de privilegio del varón en la esfera pública occidental, Marlow sortea el escollo de la auto- justificación. Al fin y al cabo, él, como hombre, es depositario de un discurso implícitamente legitimado.

La forcé de Pordre masculin se voit au fait qu'il se passe de justification: la visión androcentrique s'impose comme neutre et n'a pas besoin de s'énoncer dans des discours visant á la légitimer. (Bourdieu, 1998:15)

Conquistar, descubrir, gestionar y establecer el orden sobre lo disperso son, al fin y al cabo, tareas tradicionalmente asociadas a figuras masculinas. Si la mujer desea participar de las mismas, ha de hacerlo desde posiciones periféricas (como mera espectadora), sirviendo incondicionalmente al conquistador. Un buen ejemplo de ello es la tía amantísima de Marlow, dispuesta a todo tipo de sacrificio con tal de participar del proceso de glorificación de su sobrino.

Marlow's introduction of his aunt, by mocking her intercession with the Company on his behalf, reflects the patriarchal ideology excluding woraen from the man's sphere. Although Marlow prides himself on going "on my own legs" [...], his desire for a position with the Company forces a new approach [...]. Despite what is implied here- that no woman could have influence in such male matters- Marlow's aunt does get him the job he wants. To conceal the consequent implications, his own powerlessness, Marlow mocks his aunt's efforts [...] In this way he maintains his view that the world of experience is and should be a man's world. (Smith, 1989: 189-190)

Separada de este personaje no sólo por la distancia que impone la ficción, sino también por décadas de valiosos avances en pos de la igualdad social, Lejeune se sitúa en la primera línea de una especie de frente de batalla imaginario. Con ella, la mujer abandona la retaguardia para hundirse en el caos de las trincheras. Es tiempo para ella de dejar atrás los roles heredados, transgrediéndolos y subvirtiéndolos. En una época en la que los barcos ya no surcan el Congo en dirección al corazón de las tinieblas, la autora belga toma el relevo de Marlow al timón de su propio libro, rellenando río arriba páginas y páginas que sirven para dotar de contenido el relampagueo inicial que la empujó a sus treinta y cuatro años a luchar contra la oscuridad de lo inefable. 
Perdue Pillusion de retrouver blanche la page du commencement, $¡ 1$ s'agit pour I'áme révoltée de nouer avec l'intellect un tout autre rapport que celui de colonisée á colonisateur. (Lejeune, 1993:21)

La disparidad de las estrategias desarrolladas por estos dos seres en su lucha frente al vacío aniquilador estriba no sólo en los atributos de los que disponen en sus respectivos procesos de conquista, sino en los matices que se desprenden de sus luchas contra la luz cegadora del espacio en blanco sobrescrito con la palabra negra de la alteridad (del colonizado y de la mujer). Marlow nace a la necesidad de hacerse un nombre, de contribuir a la causa del país en el que cree tras observar recurrentemente los espacios en blanco que muestran sus mapas infantiles.

At the time there were many blank spaces on the earth, and when I saw one that looked particularly inviting on a map (but they all look that) I would put my finger on it and say. When I grow up I will go there. (Conrad, 1995: 66)

Tras una etapa vital más o menos errática, la posibilidad de hacer carrera como expedicionario- marinero en África lo seduce enormemente. Una epifanía comparable al cortocircuito existencial experimentado por Lejeune ("un court- circuit de [sa] vie avec la Vie”, 1993: 54) y que, de forma espontánea, la impulsó a emprender un camino difícil, enfrentándose a la incertidumbre del mismo y ansiando sus frutos: una identidad definida y acabada.

[...]La vraie vie de Pénonciatrice ne commenee pas par celie de Claire Lejeune, née á Havre prés de Mons en 1926, mais par celle de l'écrivaine née avec récriture, sujet advenant á sa conscience de sujet gráce á la possibilité d'une énonciation. (Renouprez, 2003: 183)

Un acontecimiento banal, casi intrascendente, despierta las conciencias adormecidas de ambos. Como si de la mítica magdalena proustiana se tratase, la carta de navegación y la poesía constituyen respectivamente dos estímulos físicos a un proceso de exploración y autoexploración que se anuncia tortuoso y complejo. El movimiento de búsqueda identitaria iniciado tanto por el personaje de Conrad como por la escritora belga los hace especialmente sensibles a una cierta fascinación por lo desconocido. La urgencia de una reafirmación personal los acerca, pues, al vértigo del terreno árido. Sus respectivas actividades están inspiradas por la necesidad de reivindicar su aptitud para el control del mismo.

Como si de una transposición del rol biológico desempeñado por cada uno de los sexos en el proceso procreador se tratase, el explorador busca, pues, preservar su linaje, transmitir su legado genético- cultural. Justificando su tarea colonizadora en función a valores cercanos a la filantropía social, Marlow encama una ambición mucho más primitiva e instintiva. $\mathrm{Al}$ internarse en las selvas africanas pretende, en definitiva, fertilizar el útero vacío que a sus ojos ofrece ese inmaculado territorio. Este peculiar conquistador $-y$ a la vez autor de unas cuantas páginas del cuaderno de viaje que es para él África- encaja en la teoría desarrollada por Gilbert y Gubar (1984: 6) a propósito del trabajo del hombre de letras: 
[...] The relationship "of the masculine self with the feminine-masculine work is also an autoerotic act... a kind of Creative onanism in which through the use of the phallic pen on the 'puré space' ofthe virgin page... the self is continually spent and wasted...

La imagen de la urgencia casi animal por garantizar la supervivencia de la especie mediante la cópula corresponde metafóricamente al ansia de las metrópolis europeas y de sus “emisarios de la luz" (Conrad, 2005: 26) por trascender no sólo las fronteras de sus respectivos países, sino también las barreras del tiempo. Adoctrinar, convertir, redimir o "liberar a millones de ignorantes de su horrible destino" (Conrad, ib id.) no son más que fórmulas eufemísticas para legitimar la violación perpetrada a las colonias.

Echando mano de un nuevo símil sexual, la escritora bien podría representar a esa víctima del abuso prolongado por parte del poder falocrático que, en lugar de plegarse al deseo del mismo (tal sería, durante décadas, el ejemplo de las poblaciones africanas), se debate por expulsar de su seno al elemento agresor. La revuelta suprema del buen salvaje robinsoniano en su versión femenina. ¿Y qué mejor manera de hacerlo que adueñándose a su vez del vacío, de la nada o del útero virginal que ofrecen ante sí no ya las tierras lejanas, sino las hojas de su propio cuaderno de notas? El expolio de estas tierras obedece a la necesidad experimentada por las fuerzas continentales de desplazar cualquier elemento indígena que pudiese perturbar su estrategia de apropiación y dominación de la oscuridad selvática. ¿Cómo enfrentarse a un vacío absoluto que no es tal? Según Kathryn Marie Smith, Marlow fracasará en su ambición de iluminar el mundo desconocido con la luz de la heterogenia europea. La causa es "Marlow's inability to keep lightness and darkness sepárate (such as when the supposedly puré, white Intended is surrounded by darkness)" (Smith, 2009: 9).

Es por ello que, arrasando con todo vestigio de las culturas y los sistemas sociales preexistentes, el hombre colonizador preparaba un lienzo idóneo sobre el que pintar sus señas y expandir su pegada. Un exterminio del que participa Marlow en su viaje al Congo, mientras que su contrapunto en este análisis, Claire Lejeune, se enfrenta a un panorama despejado que ella misma se brinda a través de la actividad literaria. El agente de la Compañía belga debe 'desbrozar' el terreno que ha de conquistar antes de ponerse en marcha, mientras que, por su parte, el cuaderno de escritura no contiene trazo alguno. Un arma de doble filo pues, si bien Marlow es instado en su trabajo a seguir una serie de directrices preestablecidas, Lejeune se enfrenta a ello sin más guía que el respeto a ciertas normas intrínsecas al campo literario en el que se mueve (o habitus, según la terminología de Bourdieu).

Neutralizando el influjo del falo -o faro- colonizador y todopoderoso, la literata se hace con las riendas de su propio destino. Ambicionando reescribir su propia historia o, mejor dicho, trazar una nueva historia exenta de principios excluyentes (la post-historia), un profundo abismo se abre ante Claire Lejeune. La fragmentación, la ausencia de guías o patrones, la impulsan a erigirse en legisladora de su propia suerte. Si bien Marlow aspira a incorporar a los habitantes del limbo africano (entre el espacio blanco del mapa y la negrura de la selva inhóspita) al reino de la civilización, Lejeune pretende aglutinar en su propia figura al conquistador y al conquistado. Habitante de la ruptura, la autora belga ansia ampararse del poder productivo y regenerador del falo simbólico. La diferencia estriba en el papel desempeñado por la fuerza dentro del proceso de creación llevado a cabo por el personaje 
y la escritora. Mientras que el enviado de la Compañía se sirve de numerosas estrategias de dudosa ortodoxia (como los ya mencionados juegos de influencias manejados por su tía) para alcanzar su propósito -participar de la tarea colonizadora allén de los mares-, la autora belga debe enfrentarse al páramo literario sin mayor apoyo que el de una naciente conciencia feminista.

Iniciando un juego subversivo en tomo a uno de los principales símbolos asociados al trabajo femenino -el huso y la meca-, Lejeune hila su discurso poético- ensayístico como si de una labor de patchwork se tratase. Diversos fragmentos, cual retales, se entretejen y enmarañan en Le livre de la sceur. Cosiendo párrafos e ideas, la escritora llena de impulso reivindicativo este molde inspirado en la pasiva costura femenina, desarrollando lo que ella denomina "pensée tricoteuse" (1993: 10). Un collage filosófico, un work in progress híbrido que se opone al rígido y lineal reparto de las tierras africanas trazado por las potencias europeas. Marlow participa, por su parte, de una tarea de costura destructiva, secesionista, que rasga los retazos de un mismo continente y que se convierte en el claro exponente de una voluntad de constmcción supranacional en base a valores belicosos.

La tarea colonizadora de signo masculino responde -en la figura del Marlow 'conradiano' - a la necesidad de dejar su impronta sobre la tierra lejana. La femenina, al de poseer una impronta propia que legitime su paso por el terreno vacío que ha sido a sus ojos su propia existencia. Aquél aspira a traspasar los límites físicos que asfixian su ambición personal. Esta, sin embargo, busca trascender las barreras íntimas impuestas a sus congéneres a lo largo de los siglos. Dos posiciones divergentes sintetizadas en un frente común ante sendos desiertos, ya sean geográficos o culturales.

La epifanía identitaria de Marlow en la obra de Conrad ha sido objeto de innumerables estudios (desde Hawthom -1990- a Eagleton -2005-). La ascesis hacia una conciencia propia sobre el proceso colonizador, la vida de los indígenas y el papel del hombre blanco en Africa constituyen la esencia de su relato. Iluminado por la oscuridad del continente desconocido, el personaje desgrana el proceso de aprehensión y ocupación del mismo. Dando nombre a ríos y pueblos, delimitando fronteras y lindes de estas exóticas extensiones de las metrópolis europeas, Marlow participa del ansia de reivindicación nacional que inflamaba en aquella época a las grandes potencias. Enarbolando la bandera británica enarbola un 'ego' en fase de cambio. Escribe una página en su libro vital así como en la historia general británica. Como si de un diario o una hoja de ruta se tratase, retrata su evolución personal en el espacio en blanco que le ofrece la selva congoleña.

Dar nombres otorga al eminente colonizador una cierta posición preeminente frente al indígena. La escritora, conquistadora de su propio ser inexplorado, busca darse un nombre, una identidad, un yo acabado. Autonombrarse significa reconocerse como mujer y como agente cultural. Y desembarazarse de las artificiosas categorizaciones de io femenino' promovidas por el poder patriarcal pasa para ella por tomar las riendas de su propio destino. Decirse, explicarse, entenderse y mostrarse a los demás lleva a Lejeune a una literatura que explota el margen de experimentación ofrecido por el blanco nuclear de la páginaborrador. El mismo espectro que se abre ante Marlow al enfrentarse al corazón de las tinieblas, convertido ahora en un resorte de gran productividad. Sin embargo, mientras que el colonizador se ve paralizado, luego seducido por el influjo de la oscuridad, la escritora 
belga encuentra estímulo inmediato en la cara oculta de las cosas, extrapolando los términos de Martine Renouprez y Danielle Bajomée (2009: 3).

Personaje de ficción y escritora, colonizador y feminista, ambos encuentran en el baldío, en el terreno fangoso de lo inexplorado, un refugio seguro en el que abrigar el germen de una identidad naciente. Al fin y al cabo, tanto la experiencia africana como el trabajo literario no son más que dos habitáculos, dos 'rooms of one's own' en las que resguardarse, unos cuartos en los que entregarse al modelado del 'yo', del 'nosotros'. El espacio en blanco constituye, pues, un cruce de caminos en el que confluyen dos modelos de creación identitaria y sobre el que Lejeune y Marlow, "apatrides du néant” (Las Vergnas, 1957: 140), desarrollan discursos de la más pura hermenéutica aplicada a lo íntimo. Hermanados por la ansiedad común frente al reto creativo y auto- creativo, sus respectivas experiencias de reapropiación del vacío quedan retratadas en una afirmación de la escritora belga, inspirándose en Virginia Woolf: "seeurs etfréresy ont leur chambre á soi. La grande salle est commune" (1993: 9).

\section{REFERENCIAS BIBLIOGRÁFICAS}

Bajomée, D. y M. Renouprez. 2009. “ In memoriam Claire Lejeune ” en Cahiers internationaux de symbolisme. Numéro spécial « Tempo di Roma »: 3-4. BOURDIEU, Pierre. 1998. La domination masculine. París: Seuil.

Cixous, H. 1977. "La venue á 1 'écriture" en CIXOUS, Héléne, GAGNON, Madeleine y Annie LECLERC. La venue á l'écriture. París: Union Générale d'Éditions : 756. COLUNGA, Alberto y Laurentio TURRADO (eds.). 2002. Biblia sacra, iuxta vulgatam clementinam. Madrid. Editorial Católica.

ConRAD, J. (1902). 2005. El corazón de las tinieblas. Trad. S. Pitol. Madrid: Ed. Comunicación y Publicaciones.

Conrad, J. (1902). 1995. Heart of Darkness. Canadá: Broadview literary texts.

GilBerT, S. M. y S. GUBAR. 1984. The madwoman in the attic. The woman writer and the nineteenth- century literary imagination. New Haven / Londres: Yale University Press.

Higonnet, M. y alii (eds.). 1987. Behind the lines. Gender and the Two World Wars. New Haven / Londres: Yale University Press.

LAGUERRE, O. 1905. Qu'est-ce que le féminisme? Lyon: Société d'éducation et d'action féministes.

LAS Vergnas, R. 1957. Joseph Conrad romancier de l'exil. Lyon: Éditions Emmanuel Vitte.

Lejeune, C. 1993. Le livre de la sœur. Bruxelas: Éditions Labor.

Panagopoulos, N. 1998. The fiction of Joseph Conrad. Frankfurt am Main: Peter Lang.

PHILLIPS, S. D. 1991. «Meaning and Structure in Social Movements: Mapping the Network of National Canadian Women's Organizations». Canadian Journal of 
Political Science / Revue canadienne de science politique. Vol. 24. No. 4: 755782.

Renouprez, M. 2003. "La mémoire et l'oubli dans les essais de Claire Lejeune” en Estela de la Torre y alii. (eds.). L'autobiographie dans l'espace francophone. /- La Belgique. Cádiz: Servicio de Publicaciones Universidad de Cádiz : 177-202.

Russ, J. 1998. Le tragique créateur. Qui a peur du nihilisme? Paris: Armand Colin.

Sмith, J. M. 1989. “'Too Beautiful Altogether': Patriarchal Ideology in HD” en Ross C. Murfin. (ed.) Joseph Conrad. Heart of Darkness. A Case Study in Contemporary Criticism. Nueva York: St Martin's Press.

Sмiтн, K. M. 2009. Revis(it)ing Joseph Conrad's Heart of Darkness: women, symbolism, and resistance. (Tesis de doctorado- Florida Atlantic University), [En línea]. Disponible en: http7/digitool.fcla.edu/R/?func:=dbin-iump-full\&object

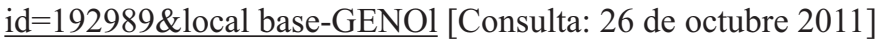

Torres Feijo, E. L. 2004. « Contributos sobre o objecto de estudo e metodologia sistémica. Sistemas literarios e literaturas nacionais» en Anxo Abuin González y Anxo Tarrio Varela, (eds.). Bases metodolóxicas para unha historia comparada das literaturas na Península Ibérica. Santiago de Compostela: USC. 423- 444. 